\title{
Outcomes of the rotating hinge knee in revision total knee arthroplasty with a median follow-up of 6.2 years
}

\author{
Jake von Hintze ${ }^{1 *}$, Mika Niemeläinen $^{1}$, Harri Sintonen ${ }^{2}$, Jyrki Nieminen ${ }^{1}$ and Antti Eskelinen ${ }^{1}$
}

\begin{abstract}
Background: The purpose of this study was to determine the mid-term clinical, radiographic and health-related quality of life (HRQoL) outcomes and define the survival rate in patients who had undergone revision total knee arthroplasty (TKA) using the single rotating hinged knee (RHK) design.

Methods: Between January 2004 and December 2013, 125 revision TKAs were performed at our institution using the single RHK implant. We conducted both a retrospective analysis of prospectively collected outcome data of these patients and a prospective follow-up study of all 39 living patients (41 knees). The follow-up phase included an optional extra follow-up visit, PROM questionnaires, and plain radiographs.

Results: The ten-year Kaplan-Meier survival rate of the revision RHK knees was 81.7\% (95\% Cl 71.9-91.6\%) with rerevision for any reason as the endpoint. Overall, 15 knees (12\% of the total) underwent re-revision surgery during the follow-up. The median follow-up was 6.2 years (range, $0-12.7$ years) post-operatively for the baseline group. One mechanical hinge mechanism-related failure occurred without any history of trauma or infection. At the time of the final follow-up, the majority of patients evinced a fairly good clinical outcome measured with patient-reported outcome measures and none of the components were radiographically loose.

Conclusion: We found that in patients undergoing complex revision TKA, fairly good functional outcome and quality of life can be achieved using an RHK implant. Further, it seems that in this type of patient cohort, revision TKA using an RHK implant relieves pain more than it improves ability to function. The NexGen ${ }^{\circledR}$ RHK design can be regarded as a suitable option in complex revision TKA.
\end{abstract}

Keywords: Revision total knee arthroplasty, Knee replacement, Rotating hinged knee, Hinged knee, Patient-reported outcome measures, Health-related quality of life

\section{Background}

In recent years, the incidence of total knee arthroplasty (TKA) has increased worldwide [1-4]. Some studies have predicted that the number of TKA procedures and the subsequent revision burden may increase further in

* Correspondence: jake.vonhintze@fimnet.fi

${ }^{1}$ Coxa Hospital for Joint Replacement, and Faculty of Medicine and Health Technologies, Tampere University, Niveltie 4, 33520 Tampere, Finland

Full list of author information is available at the end of the article future, which emphasizes the importance of the successful outcome of revision TKA [5-7].

Instability is one of the most frequent causes of knee revision and re-revision along with aseptic loosening and infections [1, 2, 4, 8, 9]. Revision of TKA implants with varying levels of constraint are available to secure knee stability after revision. In the revision or re-revision of TKA patients, the surgeon may confront severe perioperative deformities as well as bony and/or ligament deficiencies. To achieve adequate stability and ideal final

C C The Author(s). 2021 Open Access This article is licensed under a Creative Commons Attribution 4.0 International License, which permits use, sharing, adaptation, distribution and reproduction in any medium or format, as long as you give appropriate credit to the original author(s) and the source, provide a link to the Creative Commons licence, and indicate if changes were made. The images or other third party material in this article are included in the article's Creative Commons licence, unless indicated otherwise in a credit line to the material. If material is not included in the article's Creative Commons licence and your intended use is not permitted by statutory regulation or exceeds the permitted use, you will need to obtain permission directly from the copyright holder. To view a copy of this licence, visit http://creativecommons.org/licenses/by/4.0/. The Creative Commons Public Domain Dedication waiver (http://creativecommons.org/publicdomain/zero/1.0/) applies to the data made available in this article, unless otherwise stated in a credit line to the data. 
outcome, these complex clinical situations may require hinged knee implants. Hinged TKA designs are also used in knees with impaired extensor mechanism, ligamentous laxity producing painful hyperextension of the knee or in patients undergoing oncologic surgery [10-12].

Historically, aseptic loosening occurred more often with hinged knee implants that prohibited rotational motion. These models caused much unwanted stress at the prosthesis-bone interface or on the implant itself, leading to implant failure $[10,11]$. To prevent such failures, contemporary hinged knee implant designs allow rotational motion. The range of rotation and how weight is transmitted through the knee depends on the type of hinged knee implant [10].

In the literature, recently published rotating hinged knee implant studies are difficult to compare because of their heterogeneity $[11,13]$. Indeed, rotating hinged knee studies are often differentiated by indications (aseptic/ septic cases), type of implant, or cohort patients (primary/revision). More clinical evidence is therefore needed on the safety and durability of these commonly used knee replacements in revision knee arthroplasties.

The purpose of this study was to determine the midterm clinical, radiographic, and health-related quality of life (HRQoL) outcomes in patients who underwent revision TKA using the single rotating hinged knee (RHK) design at our institution between January 2004 and December 2013.

\section{Study design and methods}

From January 2004 to December 2013, 125 revision TKAs were performed at our institution using the NexGen ${ }^{\circ}$ RHK implant. The study site is an academic high-volume tertiary referral center with an annual volume of approximately 150 revision TKAs.

This study comprised three phases: first, a prospective follow-up study of all the surviving patients of this cohort was conducted. Second, a retrospective analysis of the prospectively collected outcome data recorded into the electronical joint replacement database at our institution was carried out. Third, information on possible revision surgeries that might have been performed elsewhere, and thus not recorded into our own database, was crosschecked from the Finnish Arthroplasty Register.

All RHK revision knee arthroplasties were performed using the medial parapatellar approach and a tourniquet was also routinely used. TKAs were carried out under spinal anesthesia in combination with intravenous sedation. General anesthesia was only used if there was a contraindication to spinal anesthesia. Immediate, full weight-bearing was allowed, and all patients were mobilized on the first postoperative day. An antithrombotic prophylaxis with low-molecular-weight heparin, enoxaparin, was administered for 4 weeks postoperatively. All details of perioperative care and possible complications were recorded in the hospital's electronical database in a routine manner. In 48 knees (38\%), the patella was resurfaced in the revision TKA. In 25 knees (20\%), the patella had already been resurfaced in the primary TKA operation. Cemented femoral and tibial components were used in all operations, and the choice between cemented and uncemented stems was based on surgeon preference. The trabecular metal cones were used in 13 cases $(10 \%)$. At the baseline of the study, 119 patients (125 knees) were included in the retrospective analysis, where all the demographics, surgery reports, first postoperative visits (at 2-3 months), possible post-operative complications, and adverse events as well as reasons for revisions were obtained from the medical records and the hospital's electronical clinical database. Information on possible revision surgeries performed on patients elsewhere who were lost to follow-up (18 patients, 18 knees) was cross-checked from the Finnish Arthroplasty Register [4].

In the prospective study phase, an extra follow-up visit was scheduled between 4 and 14 years post-operatively, depending on the year of the index operation. All of the 59 living and unrevised patients (61 knees) were recruited by telephone for an extra follow-up visit at our outpatient clinic (Fig. 1). In total, 39 patients (41 knees) agreed to participate in the follow-up phase of this study. Those patients who were unable to attend the extra follow-up visit received a set of PROM questionnaires by surface mail and were asked to visit their nearest health care provider for plain radiographs to be taken. The extra follow-up visit included plain radiographs of the operated joint, clinical assessment by a physiotherapist, and the use of PROMs, i.e., the Oxford Knee Score (OKS), the Knee Injury and Osteoarthritis Outcome Score (KOOS), the 15D (generic measure of healthrelated quality of life), and the Forgotten Joint Score (FJS).

\section{Radiographic evaluation Preoperative}

Radiographic findings, such as osteolytic defects and stability of the patella, were evaluated from the preoperative radiographs. Pre-revision bone defects were classified according to Anderson Orthopaedic Research Institute (AORI) classification [14] and these classifications were compared to peroperative findings for final assessment. The stability of the patella was examined from the skyline patellar radiographs. All patient records and pre-operative radiographs were examined by the first author who had not been involved in the revision surgeries and had not met the patients during the follow-up visits. To estimate the reliability of the measurements, a sample $(n=20)$ of the pre-operative radiographs was later reviewed by an experienced orthopaedic surgeon who was blinded to the original measurements. 


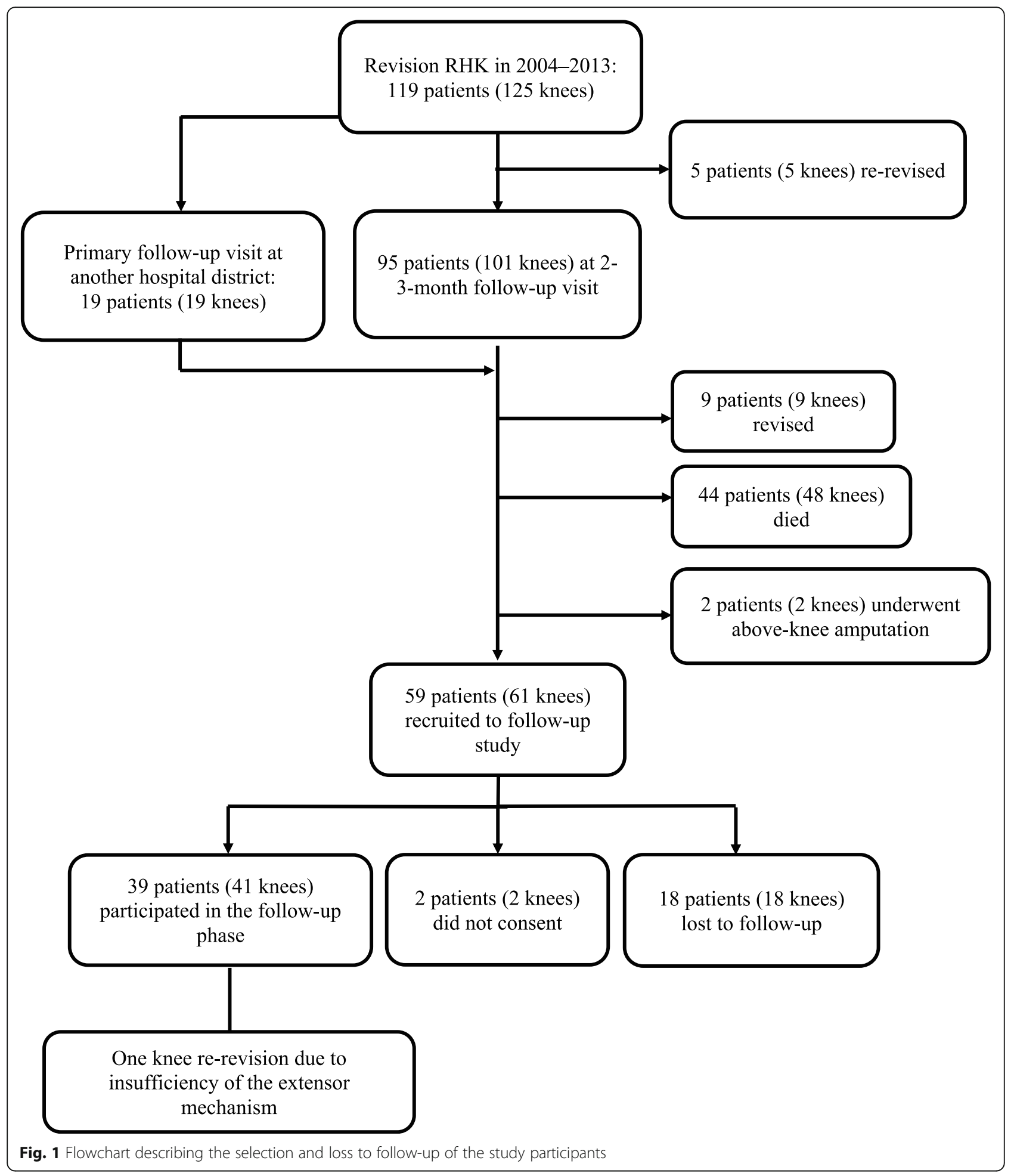

\section{Postoperative}

All postoperative plain radiographs from the extra followup were evaluated by two senior orthopaedic surgeons (coauthors JN and AE). Radiographic evaluation was performed from standardized weight-bearing antero-posterior (AP), lateral, and skyline patellar views. Radiographs were assessed for the presence of radiolucent lines or osteolytic defects.

\section{Patient-reported outcome measures}

Health-related quality of life (HRQoL) was measured using the comprehensive generic $15 \mathrm{D}$ instrument. The 
instrument combines the advantages of a profile and a preference-based single index measure. The 15D instrument includes the following 15 dimensions: mobility, vision, hearing, breathing, sleeping, eating, speech, excretion, usual activities, mental function, discomfort and symptoms, depression, distress, vitality, and sexual activity. For each dimension, the respondent chooses one of the five ordinal levels that best describe their state of health at the time (best $=1$; worst $=5$ ). The single index score $(15 \mathrm{D}$ score) represents the overall HRQoL on a $0-1$ scale $(1=$ full health, $0=$ being dead). The dimension level values reflect the goodness of the levels relative to no problems on the dimension $(=1)$ and to being dead $(=0)$. These values are then calculated from the health state descriptive system (questionnaire) by using a set of population-based preference or utility weights. Mean dimension level values are used to draw 15D profiles for groups [15]. The minimum clinically important change or difference in the 15D score has been estimated to be \pm 0.015 on the basis that people can, on average, feel such a difference [16].

We compared our study population's $15 \mathrm{D}$ results to those of an age- and gender-standardized sample of the general Finnish population $(n=4052)$ taken from the Health 2011 Survey carried out by the National Institute for Health and Welfare of Finland [17].

The OKS and the KOOS have been widely used to assess the outcomes of knee replacements $[18,19]$. In this study, the OKS was categorized into four different grades: poor (0-26), fair (27-33), good (34-41), and excellent $(42-48)[18]$. The KOOS is an extension to the WOMAC Osteoarthritis index and includes five separately scored subscales. The subscales are Pain, other Symptoms, Function in daily living (ADL), Function in sport and recreation, and knee-related quality of life [20]. Forgotten Joint Score (FJS) assesses the patient's ability to forget the replaced joint while performing recreational activities and in daily life. A higher degree of "forgetting" the joint indicates a better outcome of surgery [20].

The Kaplan-Meier (K-M) analysis was performed to assess the survival rate of the RHK implant. Both survival rates and 95\% confidence intervals $(\mathrm{CI})$ were derived from $\mathrm{K}-\mathrm{M}$ models. The independent samples t-test was used to test the statistical significance of the differences in the mean 15D results between the groups. Statistical significance was set at $p<0.05$. The statistical analysis was performed with SPSS Statistics for Mac (version 25.0). Competing risk analysis was performed with $\mathrm{R}$ (version 4.0.2). The study was funded by an institutional grant from Zimmer Biomet Inc. (Warsaw, IN, USA). The study was approved by the local ethical committee (R17010).

\section{Results}

The baseline study group consisted of 86 women (91 knees) and 33 men (34 knees) with a median age of 71.7 years (range, 31-95 years) at the time of revision TKA. Five females and one male patient underwent bilateral revision TKA (RHK on both sides). In the final follow-up group, most of the patients were women $(72 \%, n=28 / 39)$. The median follow-up was 7.3 years (range, 4.0-12.7 years) at the time of the final follow-up. Demographics, revision indications, and pre-revision bone defects are summarized in Table 1 . The most important indication for revision was instability $(n=54,43.2 \%)$. Pre-revision bone defects were mostly grade 1 both on the tibial $(n=87$, $69.6 \%)$ as well as on the femoral side $(n=90,72.0 \%)$ according to the AORI classification.

\section{Clinical outcome and PROMs in the final follow-up group} OKS was good or excellent in a slight majority of patients (51\%, 21 knees), moderate in 6 knees, and poor in 14 knees at the time of the extra follow-up visit. The median OKS was $29(n=33$, range, $8-48)$. The median KOOS for Pain was $75(n=34$, range, 19-100), Symptoms 73 ( $n=33$, range, 18-100), ADL $69(n=34$, range, 7-100), Sport/Rec $18(n=33$, range, $0-100)$, and QOL $44(n=33$, range, $6-100)$ at the time of final follow-up. The median FJS was 33 ( $n=34$, range, $0-100)$.

The mean 15D score of the patients was 0.806 (range, $0.523-1.000)$ at the time of the final follow-up. The ageand gender-standardized control population average was 0.877 (range, $0.778-0.943$ ). This difference is both clinically important and statistically significant $(p=0.002)$. The mean level values of the dimensions of the patients compared to those of the age- and the genderstandardized general population are shown in Fig. 2.

On average, there was a trend for RHK patients to be better off than the control population on the dimension of mental function, but the difference was not statistically significant $(p=0.098)$. RHK patients were, however, statistically significantly worse off than the control population on the dimensions of mobility $(p<0.001)$, usual activities $(p<0.001)$, and discomfort and symptoms $(p=$ 0.008).

At the time of the final follow-up, plain radiographs were available for 37 patients ( 39 knees). One patient (1 knee) had a radiolucent line in the cement-bone interface next to the medial condyle of the tibia; components were stable and no osteolysis was seen. Two patients (2 knees) had mild radiolucencies around the proximal part of the femoral stem, and one of them also had distal pedestal bone formation, which is typical for uncemented stems. None of the components were radiographically loose.

\section{Revisions, survival rate and complications in the baseline group}

In total, 15 knees (12\% of the total) underwent rerevision surgery during the follow-up (Table 2). In eight 
Table 1 Demographics of study population

\begin{tabular}{|c|c|c|c|c|}
\hline \multirow[b]{2}{*}{ N of knees (patients) } & \multicolumn{2}{|c|}{ The baseline } & \multicolumn{2}{|c|}{ Final follow-up } \\
\hline & 125 & 119 & 41 & 39 \\
\hline Age (median, range) & 71.7 & $31.2-95.3$ & 67.1 & $42.0-85.1$ \\
\hline Body mass index (median, range) & 29.3 & $18.8-52.0$ & 30.6 & $23.1-43.0$ \\
\hline Follow-up, years (median, range) & 6.2 & $0.0-12.7$ & 7.3 & $4.0-12.7$ \\
\hline Females (knees, \%) & 91 & $73 \%$ & 30 & $73 \%$ \\
\hline Number of previous knee surgeries (median, range) ${ }^{a}$ & 2 & $1-6$ & 2 & $1-5$ \\
\hline \multicolumn{5}{|l|}{ Indications for revision RHK (knees), N (\%) } \\
\hline Instability & 54 & $43.2 \%$ & 22 & $53.7 \%$ \\
\hline Prosthetic joint infection & 26 & $20.8 \%$ & 6 & $14.6 \%$ \\
\hline Loosening, wear and osteolysis & 20 & $16.0 \%$ & 3 & $7.3 \%$ \\
\hline Periprosthetic fracture & 11 & $8.8 \%$ & 3 & $7.3 \%$ \\
\hline Complication of the extensor mechanism ${ }^{b}$ & 7 & $5.6 \%$ & 2 & $4.9 \%$ \\
\hline Malalignment & 6 & $4.8 \%$ & 4 & $9.8 \%$ \\
\hline Arthrofibrosis & 1 & $0.8 \%$ & 1 & $2.4 \%$ \\
\hline \multicolumn{5}{|l|}{ Stability of patella preoperatively, N (\%) } \\
\hline Stable & 66 & $52.8 \%$ & 21 & $51.2 \%$ \\
\hline Subluxation & 11 & $8.8 \%$ & 3 & $7.3 \%$ \\
\hline Chronic dislocation & 11 & $8.8 \%$ & 5 & $12.2 \%$ \\
\hline Fragmentation/Demineralization & 4 & $3.2 \%$ & 2 & $4.8 \%$ \\
\hline Girdlestone/Spacer/Flap & 4 & $3.2 \%$ & 1 & $2.4 \%$ \\
\hline Fracture & 3 & $2.4 \%$ & 1 & $2.4 \%$ \\
\hline \multicolumn{5}{|l|}{ Instability of knee, N (\%) } \\
\hline Antero-Posterior & 47 & $37.6 \%$ & 15 & $36.6 \%$ \\
\hline Medio-Lateral & 82 & $65.6 \%$ & 28 & $68.3 \%$ \\
\hline \multicolumn{5}{|l|}{ Pre-revision bone defects $(\mathrm{AORI}, \mathrm{N}(\%))^{\mathrm{C}}$} \\
\hline \multicolumn{5}{|l|}{ Tibia } \\
\hline grade 1 & 87 & $69.6 \%$ & 30 & 73.2 \\
\hline grade $2 \mathrm{a}$ & 12 & $9.6 \%$ & 5 & $12.2 \%$ \\
\hline grade $2 b$ & 11 & $8.8 \%$ & 3 & $7.3 \%$ \\
\hline grade 3 & 15 & $12.0 \%$ & 3 & $7.3 \%$ \\
\hline \multicolumn{5}{|l|}{ Femur } \\
\hline grade 1 & 90 & $72.0 \%$ & 34 & $82.9 \%$ \\
\hline grade $2 a$ & 10 & $8.0 \%$ & 2 & $4.9 \%$ \\
\hline grade $2 b$ & 9 & $7.2 \%$ & 1 & $2.4 \%$ \\
\hline grade 3 & 16 & $12.8 \%$ & 4 & $9.8 \%$ \\
\hline
\end{tabular}

ancluding the index primary operation and possibly the spacer procedure

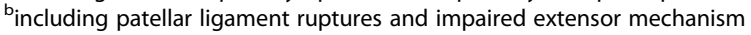

${ }^{c}$ According to Anderson Orthopaedic Research Institute (AORI) classification.

cases, the reason for re-revision surgery was prosthetic joint infection (PJI). One mechanical hinge mechanismrelated complication led to re-revision surgery: both the tibial cone and also the anterior part of the femoral hinge-post had fractured in that knee (See details in Table 2).

The ten-year K-M survival rate for the revision RHK implant was $81.7 \%$ (95\% CI 71.9-91.6\%) with revision for any reason as the endpoint. The ten-year K-M survival rate was $82.4 \%$ (95\% CI 72.6-92.2\%) when those revisions, in which only patellar resurfacing was performed, were excluded. Competing risk analysis for overall survival probability of arthroplasty $(40.0 \%$ at 10 years) and probability of re-revision (12.0\% at 10 years) and death (36.8\% at 10 years) as competing events is shown in Fig. 3. 


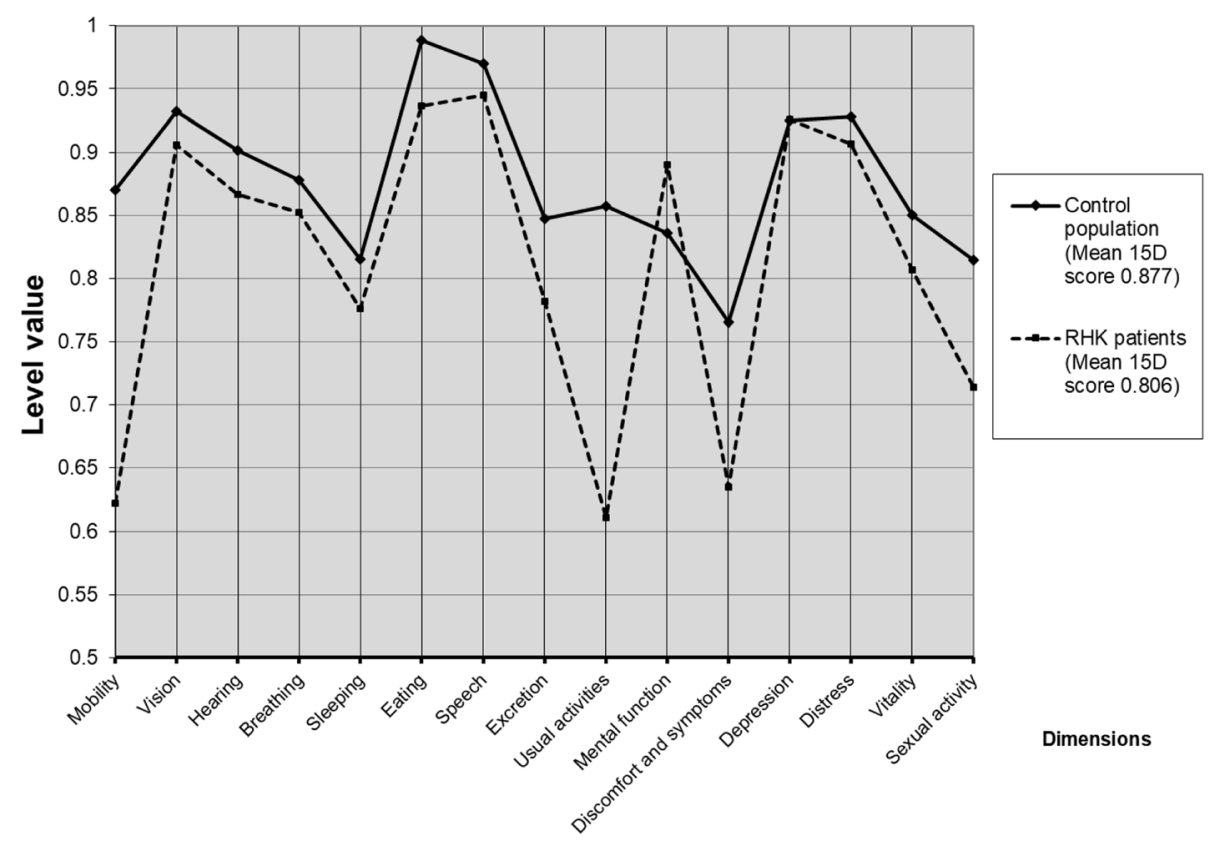

Fig. 2 Comparison of mean 15D profiles between control population and RHK group

During the follow-up, 31 postoperative complications were recorded (25\%; Additional file 1). Later on, one of these patients also underwent knee arthrodesis due to severe extensor mechanism insufficiency 5.1 years after the index operation (marked with A in Table 2 \& Additional file 1). Two other patients also had multiple complications during the follow-up (marked with $\mathrm{B}$ and $\mathrm{C}$ in Additional file 1). Two above knee amputations had to be performed: one patient underwent amputation because of critical limb ischemia (ASO) and the other one because of chronic PJI that was difficult to keep in control. These have been considered as the endpoint of survival (Additional file 1).

\section{Discussion}

In our study, we demonstrated a fair mid-term clinical outcome and also acceptable implant survivorship in patients undergoing complex revision arthroplasty using the NexGen ${ }^{\circ}$ RHK implant. A slight majority of the patients reported good or excellent OKS at the time of the final follow-up. Moreover, 39\% $(n=13 / 33)$ of the patients described their knee pain as either non-existent or very mild. However, HRQoL was worse in these patients than in the control population as measured with the 15D instrument. The ten-year K-M survival rate was 81.7\% with revision for any reason as the endpoint. Overall, 15 knees (12\% of the total) underwent re-

Table 2

\begin{tabular}{|c|c|c|c|}
\hline Revisions & Failure & Time to failure & Treatment \\
\hline 1 & Periprosthetic femoral fracture & 6.2 years & $\begin{array}{l}\text { Osteosynthesis combined with exchange of the femoral } \\
\text { component and the polyethylene insert }\end{array}$ \\
\hline 2 & Aseptic loosening (femur) & 7.2 years & Exchange of the femoral component and the tibial insert \\
\hline 3 & Prosthetic joint infection & 0.17 years & DAIR \\
\hline 4 & Arthrofibrosis & 5.8 years & $\begin{array}{l}\text { Open lysis of adhesions through medial parapatellar } \\
\text { arthrotomy }\end{array}$ \\
\hline 5 & $\begin{array}{l}\text { Mechanical hinge-related complication (without trauma); } \\
\text { fracture of the tibial cone and the anterior part of the } \\
\text { femoral hinge-post }\end{array}$ & 3.0 years & Exchange of the tibial insert and the hinge mechanism \\
\hline 6 & Patellar dislocation (traumatic) & 0.2 years & Secondary patellar resurfacing \\
\hline 7 & Rupture of the quadriceps tendon and the $\mathrm{MPFL}^{\mathrm{a}}$ & 5.1 years & Knee arthrodesis \\
\hline $8-15$ & Prosthetic joint infection & 9 days -8.7 years & 2-stage revision arthroplasty \\
\hline
\end{tabular}

a Patient had multiple complications, see Additional file 1

MPFL The medial patellofemoral ligament

$D A I R$ Debridement and implant retention 


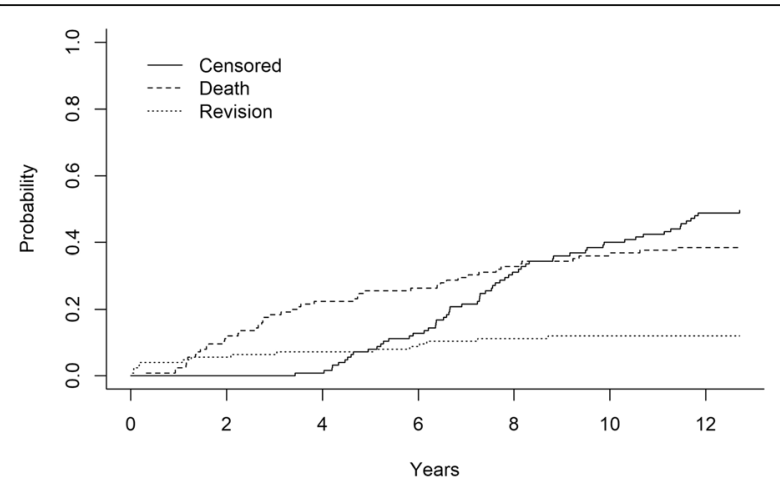

Fig. 3 Cause-specific probability and overall survival probability of arthroplasty revision and death as competing events

revision surgery during the follow-up, and the most common reason for re-revision was prosthetic joint infection (PJI; 8/15 of the cases). One mechanical failure of the hinge mechanism led to re-revision. None of the RHK implants were radiographically loose at the time of the final follow-up.

We acknowledge a few limitations in our study. First, the number of participants was low in the final clinical follow-up visit, which reduces the generalizability of our results. Medical comorbidities and overall fragility preventing patients from participating in this kind of clinical follow-up study were the main reasons given for the low participation rate. However, this is an obvious universal problem when conducting research on frail, elderly patients. Moreover, previous follow-up studies have also reported difficulties in achieving a complete follow-up for this challenging patient group [21-24]. By cross-checking the patient's re-revisions from the Finnish Arthroplasty Register, however, we were able to make sure that we had captured all the re-revisions performed on these patients and also those performed outside our hospital district on patients who were lost to our clinical follow-up. Second, the indications for knee revision surgery were variable, as both aseptic and septic revisions were included (21\%) and comorbidities were partly unknown and therefore not considered in this study. Third, the preoperative PROMS were unavailable, which made it difficult to evaluate the influence of RHK arthroplasty on symptoms, ability to act, or quality of life. Moreover, there was lack for information of stem lengths and the use of augments.

We consider that our study also has a few strengths. As far as we know, this current study is one of the largest series evaluating single rotating hinge knee implant model outcomes only in revision TKA. Moreover, the median 6.2 years follow-up can be considered satisfactory. To our knowledge, this study, which evaluated the efficacy of a single implant on revision TKA, has the largest cohort and longest follow-up for the NexGen ${ }^{\circ}$ RHK implant in the published literature [11, 21-33].
The final follow-up group reported variable OKS results. It must be noted, however, that a slight majority reported good or excellent OKS, but the total median score was 29, which can be categorized as fair [18]. Our OKS results are in accordance with previous studies [26, 33]. Böhler et al. reported an OKS of 29 (mean, $n=26$ ) for revision arthroplasty in five-year mid-term follow-up for different single rotating hinge knee implants [33]. Furthermore, Giurea et al. reported an OKS of 30 (mean, $n=62$ ) after two-year follow-up [26].

Helito et al. investigated single rotating hinge knee implants prospectively and reported the KOOS after oneyear follow-up. The study included only nine patients, however, and six of them were primary rotating hinge knee implants, and therefore it is difficult to compare them with KOOS [34]. We are unaware of any previous study that has reported the KOOS after revision RHK arthroplasty with mid-term follow-up. Our cohort's KOOS subscales reflect a good outcome for treated pain and symptoms during the follow-up.

There is a paucity of reported FJS in rotating hinge knee patients. Röhner et al. studied single hinge knee implants in primary arthroplasty and reported an FJS of 39 in the mean 20-months follow-up [35]. This is slightly less than our reported FJS. However, our study cohort comprised only revision knees, and thus a meaningful direct comparison between the results was not possible.

The mean 15D score of our RHK cohort was statistically significantly and clinically importantly worse than in the control population. The patients were worse off, especially on the dimensions of mobility, usual activities, and discomfort and symptoms. It is reasonable therefore to assume that these kinds of complex revision arthroplasty patients have difficulties when compared with the ageand gender-standardized general population. Further, RHK patients were better only on the dimension of mental function. However, the difference was not statistically significant and this might be attributable to selection bias. Patients with severe neurodegenerative diseases were lost to follow-up and this could have biased our HRQoL results. Miettinen et al. reported a retrospective study, in which QoL was assessed the 15D instrument before and after primary TKA, but the type of implants remained unknown. After TKA, mean 15D score was $0.870(n=731)$ at the time of 12 month follow-up [36]. This is markedly higher than the mean $15 \mathrm{D}$ score $(0.806)$ in our study at the time of final follow-up visit. However, a meaningful direct comparison between these results is not possible for various reasons.

Kouk et al. published a review study of rotating hinge implants for revision TKA. They evaluated studies which included more than 50 rotating hinge implants used in the revision setting. They summarized complication 
rates to have been between 7 and $63 \%$ in the previous studies [13].

In this regard, our postoperative complication rate (25\%) bears comparison with the current literature. In the current study, infections were a notable part of all the complications $29 \%(n=9 / 31)$ and of all the revisions $60 \%(n=9 / 15)$. Moreover, $32 \%(n=10 / 31)$ of all complications were related to extensor apparatus complications. It should be noted that only two of these had a preoperative well-functioning extensor mechanism (Additional file 1). These complications can be devastating and have a major influence on the ability to act [37]. Kearns et al. examined the same single RHK design (14 primary and 65 revision patients) and reported postoperative complications in 39\% of patients, which included three (13\% of all postoperative complications) mechanical hinge failures and five (21\%) extensor mechanism ruptures. Two patients had failure of their hinge-post and one had a fracture of the hinge mechanism [21]. This is more than the one mechanical failure reported in our study.

The 10 -year implant survival rate of $81.7 \%$ is comparable with the rates reported in other rotating hinge knee studies. In their meta-analysis that included 12 different studies, Yoon et al. compared the survivorships and outcomes of RHK and condylar constrained knee prostheses. The rotating hinge knee implant models were variable. The meta-analysis revealed an overall survival rate of $81.3 \%$ for all RHK implants at the mid-term (510 years) follow-up [38].

\section{Conclusion}

To conclude, we found the NexGen ${ }^{\circ}$ RHK design to be a suitable option in complex revision TKA. This implant provided fairly good functional outcome and quality of life in our cohort of patients, and the mid-term implant survivorship was acceptable in this challenging patient group. Also mechanical problems in the hinge mechanism were rare. However, Nexgen RHK should only be used in complex cases, as complications are still frequent, and the results of this design are comparable, not superior, to those previously published of other rotating hinge knee designs.

\begin{abstract}
Abbreviations
HRQoL: Health-Related Quality of Life; TKA: Total Knee Arthroplasty; RHK: Rotating Hinged Knee; PROM: Patient reported outcome measures; OKS: Oxford Knee Score; KOOS: Knee Injury and Osteoarthritis Outcome Score; FJS: Forgotten Joint Score; AORI: Anderson Orthopaedic Research Institute; PJI: Prosthetic Joint Infection; DAIR: Debridement, Antibiotics and Implant Retention; MPFL: The medial patellofemoral ligament
\end{abstract}

\section{Supplementary Information}

The online version contains supplementary material available at https://doi. org/10.1186/s12891-021-04205-9.

Additional file 1. Postoperative revision surgeries.

\section{Acknowledgements}

Not applicable.

\section{Authors'contributions}

JVH: data collection, data analysis, writing and revising the manuscript. MN: study design, writing and revising the manuscript. HS: 15D analysis, revision of manuscript. JN: study design, revision of manuscript. AE: study design, revision of manuscript. The authors read and approved the final manuscript.

\section{Funding}

The study was funded by an institutional grant from Zimmer Biomet Inc. (Warsaw, IN, USA, grant number: IRE2017-08 K). The funder had no role in the design of the study, collection, analysis or writing of the manuscript.

\section{Availability of data and materials}

The datasets generated and/or analysed during the current study are not publicly available due General Data Protection Regulation at our hospital district but are available from the corresponding author on reasonable request.

\section{Declarations}

Ethics approval and consent to participate

This study was performed according to the Helsinki declaration and approved by the Ethics Committee of Tampere University Hospital (R17010). Written informed consent was obtained from all living participants. For retrospective analysis of hospital register data of those patients who had either died or lost to follow-up, permission was obtained from the hospital's Institutional Review Board.

\section{Consent for publication}

Not applicable.

\section{Competing interests}

The author(s) disclosed receipt of the following financial support for the research, authorship, and/or publication of this article: The author AE has received research support funding from DePuy Synthes and Zimmer Biomet and speaking/presentation fee from Zimmer Biomet. Other authors have no conflicts.

\section{Author details}

${ }^{1}$ Coxa Hospital for Joint Replacement, and Faculty of Medicine and Health Technologies, Tampere University, Niveltie 4, 33520 Tampere, Finland. ${ }^{2}$ Department of Public Health, University of Helsinki, Helsinki, Finland.

Received: 21 December 2020 Accepted: 18 March 2021

Published online: 07 April 2021

\section{References}

1. Sjukhuset A, Artclinic A, Artclinic G, Arvika J, Borås B, Danderyd C, et al. Lund: the Swedish knee arthroplasty register. Annu Rep. 2020;2020 Available from: https://www.rtda.gov.rw/fileadmin/templates/publications/RWANDA_A nnual_Report_2018-2019_SHARING.pdf.

2. AOA. Australian Orthopaedic Association National Joint Replacement Registry (AOANJRR). Hip, knee \& shoulder arthroplasty: 2020 Annual Report. Adelaide: AOA; 2020.

3. Niemelälnen MJ, MäKelä KT, Robertsson $O, W$-Dahl A, Furnes $O$, Fenstad AM, et al. Different incidences of knee arthroplasty in the nordic countries: a population-based study from the nordic arthroplasty register association. Acta Orthop. 2017;88(2):173-8. https://doi.org/10.1 080/17453674.2016.1275200

4. Far, Finnish Arthroplasty Register. [cited 2021 Feb 3]. Available from: https:// www.thl.fi/far/\#index

5. Klug A, Gramlich Y, Rudert M, Drees P, Hoffmann R, Weißenberger M, Kutzner KP. The projected volume of primary and revision total knee arthroplasty will place an immense burden on future health care systems over the next 30 years. Knee Surg Sports Traumatol Arthrosc. 2020:1-12. https://doi.org/10.1007/s00167-020-06154-7. Epub ahead of print. PMID: 32671435; PMCID: PMC7362328.

6. Bozic KJ, Kamath AF, Ong K, Lau E, Kurtz S, Chan V, et al. Comparative epidemiology of Revision Arthroplasty: failed THA poses greater clinical and 
economic burdens than failed TKA. Clin Orthop Relat Res [Internet]. 2015; 473(6):2131-8. Available from:. https://doi.org/10.1007/s11999-014-4078-8.

7. Delanois RE, Mistry JB, Gwam CU, Mohamed NS, Choksi US, Mont MA. Current epidemiology of revision total knee arthroplasty in the United States. J Arthroplasty. 2017;32(9):2663-8. Available from:. https://doi.org/10.1 016/j.arth.2017.03.066.

8. Sadoghi P, Liebensteiner M, Agreiter M, Leithner A, Böhler N, Labek G. Revision surgery after total joint arthroplasty: a complication-based analysis using worldwide arthroplasty registers. J Arthroplasty. 2013;28(8):1329-32. Available from:: https://doi.org/10.1016/j.arth.2013.01.012.

9. National Joint Registry for England, Wales, Northern Ireland and Isle of Man. 17th Annual Report 2020. Natl Jt Regist. 2020; Available from: https:// reports.njicentre.org.uk/Portals/0/PDFdownloads/NJR 17th Annual Report 2020.pdf.

10. Morgan H, Battista V, Leopold SS. Constraint in primary total knee arthroplasty. J Am Acad Orthop Surg. 2005;13(8):515-24 [cited 2018 may 5]. Available from: http://www.ncbi.nlm.nih.gov/pubmed/16330513.

11. Pasquier $G$, Ehlinger $M$, Mainard $D$. The role of rotating hinge implants in revision total knee arthroplasty. EFORT Open Rev. 2019;4(6):269-78. https:// doi.org/10.1302/2058-5241.4.180070.

12. Rahman J, Hanna SA, Kayani B, Miles J, Pollock RC, Skinner JA, et al. Custom rotating hinge total knee arthroplasty in patients with poliomyelitis affected limbs. Int Orthop. 2015;39(5):833-8. https://doi.org/10.1007/s00264-014-2 $572-y$.

13. Kouk S, Rathod PA, Maheshwari AV, Deshmukh AJ. Rotating hinge prosthesis for complex revision total knee arthroplasty: a review of the literature. J Clin Orthop Trauma. 2018;9(1):29-33 Available from: http://www. sciencedirect.com/science/article/pii/S0976566217304381.

14. Panegrossi G, Ceretti M, Papalia M, Casella F, Favetti F, Falez F. Bone loss management in total knee revision surgery. Int Orthop. 2014;38(2):419-27. https://doi.org/10.1007/s00264-013-2262-1.

15. Sintonen $\mathrm{H}$. The 15D instrument of health-related quality of life: properties and applications. Ann Med. 2001;33(5):328-36 [cited 2018 may 6]Available from: http://www.ncbi.nlm.nih.gov/pubmed/11491191.

16. Alanne $S$, Roine RP, Räsänen P, Vainiola T, Sintonen H. Estimating the minimum important change in the 15D scores. Qual Life Res. 2015;24(3): 599-606. 22 [cited 2018 Aug 18]. Available from. https://doi.org/10.1007/ s11136-014-0787-4

17. Koskinen S, Lundqvist A. Ristiluoma, Noora eds. Health, functional capacity and welfare in Finland in 2011. Helsinki; 2012. [cited 2018 May 6]. Available from: https:/www.julkari.fi/bitstream/handle/10024/90832/Rap068_2012_ netti.pdf

18. Murray DW, Fitzpatrick R, Rogers K, Pandit H, Beard DJ, Carr AJ, et al. The use of the Oxford hip and knee scores. J Bone Jt Surg [Br]. 2007:89:1010-4 [cited 2018 May 7]. Available from: https://online.boneandjoint.org.uk/doi/ pdf/10.1302/0301-620X.89B8.19424.

19. Roos EM, Lohmander LS. The Knee injury and Osteoarthritis Outcome Score (KOOS): from joint injury to osteoarthritis. Health Qual Life Outcomes. 2003; 1:64 [cited 2018 may 7];Available from: http://www.ncbi.nlm.nih.gov/ pubmed/14613558.

20. Behrend H, Giesinger K, Giesinger JM, Kuster MS. The "Forgotten Joint" as the ultimate goal in joint arthroplasty: validation of a new patient-reported outcome measure. J Arthroplasty. 2012;27(3):430-436.e1 [cited 2018 May 7]Available from: https://www-sciencedirect-com.helios.uta.fi/science/article/ pii/S0883540311004670?_rdoc=1\&_fmt=high\&_origin=gateway\&_doca nchor=\&md5=b8429449ccfc9c30159a5f9aeaa92ffb\&ccp=y.

21. Kearns SM, Culp BM, Bohl DD, Sporer SM, Della Valle CJ, Levine BR. Rotating hinge implants for complex primary and revision total knee arthroplasty. J Arthroplasty. 2018;33(3):766-70 [cited 2018 may 5]. Available from: http:// www.ncbi.nlm.nih.gov/pubmed/29129618.

22. Deehan DJ, Murray J, Birdsall PD, Holland JP, Pinder IM. The role of the rotating hinge prosthesis in the salvage arthroplasty setting. J Arthroplasty. 2008;23(5):683-1 [cited 2018 Jun 20]. Available from: https:/wwwsciencedirect-com.helios.uta.fi/science/article/pii/S0883540307004354 ?_rdoc=1\&_fmt=high\&_origin=gateway\&_docanchor $=\& m d 5=b 842944$ 9ccfc9c30159a5f9aeaa92ffb.

23. Smith TH, Gad BV, Klika AK, Styron JF, Joyce TA, Barsoum WK. Comparison of mechanical and nonmechanical failure rates associated with rotating hinged total knee arthroplasty in nontumor patients. J Arthroplasty. 2013; 28(1):62-7.e1 Jan [cited 2018 Jun 20]. Available from: http://linkinghub. elsevier.com/retrieve/pii/S0883540312003178.
24. Bistolfi A, Rosso F, Crova M, Massazza G. Endo-modell rotating-hinge total knee for revision total knee arthroplasty. Orthopedics. 2013;36(10):1299-307.

25. Farid YR, Thakral R, Finn HA. Intermediate-term results of 142 single-design, rotating-Hinge Implants: frequent complications may not preclude salvage of severely affected knees. J Arthroplasty. 2015;30(12):2173-80. Available from:. https://doi.org/10.1016/j.arth.2015.06.033.

26. Giurea A, Neuhaus HJ, Miehlke R, Schuh R, Lass R, Kubista B, et al. Early results of a new rotating hinge knee implant. Biomed Res Int. 2014;2014:18. https://doi.org/10.1155/2014/948520.

27. Guenoun B, Latargez L, Freslon M, Defossez G, Salas N, Gayet LE. Complications following rotating hinge Endo-Modell (Link $\left.{ }^{\ominus}\right)$ knee arthroplasty. Orthop Traumatol Surg Res. 2009;95(7):529-36 Nov [cited 2018 Jun 20]Available from: http://inkinghub.elsevier.com/retrieve/pii/S1 877056809001479

28. Efe T, Roessler PP, Heyse TJ, Hauk C, Pahrmann C, Getgood A, et al. Midterm results after implantation of rotating-hinge knee prostheses: primary versus revision. Orthop Rev (Pavia). 2012;4(4):35 2 [cited 2018 May 5] Available from: http://www.pagepress.org/journals/index.php/or/article/ view/or.2012.e35.

29. Shen C, Lichstein PM, Austin MS, Sharkey PF, Parvizi J. Revision knee Arthroplasty for bone loss: choosing the right degree of constraint. J Arthroplasty. 2014;29(1):127-31. Available from: http://www.sciencedirect. com/science/article/pii/S088354031300346X. https://doi.org/10.1016/j.arth.2 013.04.042.

30. Baier C, Lüring C, Schaumburger J, Köck F, Beckmann J, Tingart M, et al. Assessing patient-oriented results after revision total knee arthroplasty. J Orthop Sci. 2013;18(6):955-61. Available from: https://libproxy.tuni.fi/ login?url=https://search.proquest.com/docview/1460842742?accountid= 14242. https://doi.org/10.1007/s00776-013-0467-1.

31. Joshi N, Navarro-Quilis A. Is there a place for rotating-hinge arthroplasty in knee revision surgery for aseptic loosening? J Arthroplasty. 2008;23(8):120411. Available from: http://www.sciencedirect.com/science/article/pii/S088354 03070061 10. https://doi.org/10.1016/j.arth.2007.10.016.

32. Cottino U, Abdel MP, Perry KI, Mara KC, Lewallen DG, Hanssen AD. Longterm results after total knee arthroplasty with contemporary rotating-hinge prostheses. J Bone Joint Surg Am. 2017;99(4):324-30 15 [cited 2018 Jun 20]. Available from: http://insights.ovid.com/crossref?an=00004623-20170215000006.

33. Böhler C, Kolbitsch P, Schuh R, Lass R, Kubista B, Giurea A. Midterm results of a new rotating hinge knee implant: a 5-year follow-up. Biomed Res Int. 2017;2017:7532745 [cited 2018 Jun 8]. Available from: http:/www.ncbi.nlm. nih.gov/pubmed/29376075.

34. Helito CP, Giglio PN, Cavalheiro CM, Gobbi RG, Demange MK, Camanho GL. Knee arthroplasty with rotating-hinge implant: an option for complex primary cases and revisions. Rev Bras Ortop (English Ed). 2018;53(2):151-7. Available from:. https://doi.org/10.1016/j.rboe.2017.01.010.

35. Röhner E, Benad K, Zippelius T, Kloss N, Jacob B, Kirschberg J, et al. Good clinical and radiological results of total knee arthroplasty using varus valgus constrained or rotating hinge implants in ligamentous laxity. Knee Surg Sport Traumatol Arthrosc. 2019;27(5):1665-70. Available from:. https://doi. org/10.1007/s00167-018-5307-6.

36. Miettinen HJA, Mäkirinne-Kallio N, Kröger H, Miettinen SSA. Health-related quality of life after hip and knee arthroplasty operations. Scand I Surg. 2020: 1-7. https://doi.org/10.1177/1457496920952232.

37. Courtney PM, Edmiston TA, Pflederer CT, Levine BR, Gerlinger TL. Is there any role for direct repair of extensor mechanism disruption following total knee arthroplasty? J Arthroplasty. 2018;33(7, Supplement):S244-8 Available from: http://www.sciencedirect.com/science/article/pii/S0883540317310501.

38. Yoon JR, Cheong JY, Im JT, Park PS, Park JO, Shin YS. Rotating hinge knee versus constrained condylar knee in revision total knee arthroplasty: a metaanalysis. PLoS One. 2019;14(3):1-14.

\section{Publisher's Note}

Springer Nature remains neutral with regard to jurisdictional claims in published maps and institutional affiliations. 